NCAEE 2017

National Conference on Advances in Electrical Engineering

NMAM Institute of Technology, Nitte

Vol. 5, Special Issue 2, April 2017

\title{
Comparison of two Different Approaches for Harmonic Analysis of Single Phase Inverter
}

\author{
Sathisha K ${ }^{1}$, Dr. Pinto Pius A.J. ${ }^{2}$ \\ Assistant Professor, Department of E\&E, St. Joseph Engineering College, Mangaluru, India ${ }^{1}$ \\ Professor, Department of E\&E, NMAM Institute of Technology, Nitte, Karkala, India ${ }^{2}$
}

\begin{abstract}
In this paper we present, harmonic analysis of single phase inverter based on unipolar pwm and bipolar pwm techniques. Simulation results of both the methods are also highlighted. In order to find the Total Harmonic Distortion (THD), FFT is used using mat lab/simulation software. It is found that performance of unipolar switching technique is better than bipolar switching technique in comparison of THD. It is observed that minimum value of THD of unipolar switching technique is $5.28 \%$ and Bipolar switching technique is $11.03 \%$ in case of amplitude modulation. Also in the case of frequency modulation we get $5.52 \%$ and $7.72 \%$ respectively.
\end{abstract}

Keywords: Total Harmonic Distortion; Modulation Index; Pulse width modulation.

\section{INTRODUCTION}

In recent years many research are ongoing for improving efficiency of inverter mainly by different switching techniques. Pulse width modulation technique controls, on-off time period of switches to obtain desired AC output and also helps to control the harmonics in $\mathrm{AC}$ output voltage and current of the inverter.

In Pulse width modulation technique, the output voltage and frequency of the inverter can be controlled easily by varying the conduction angle of the inverter switches. By Pulse width modulation technique one can achieve variable frequency and voltage or constant frequency and voltage output from the inverter. Some applications require variable frequency for example, speed control of motor applications requires variable frequency and electrical hammer application requires constant frequency and so on.

Switching techniques such as unipolar and bipolar were used in article [1], for analyzing the harmonics in the inverter circuit with filter. Article [2] explains how inverter can be interface with photovoltaic panels to ac network, and also paper discusses how current harmonics in inverter can be eliminated by unipolar and bipolar switching techniques. After simulation result paper concluded that for low value of switching frequency, bipolar switching techniques provide less current distraction but it is not suitable for high switching frequency. For high switching frequency, article preferred unipolar switching technique because of less power loss and less harmonics.

Authors [3] used unipolar pwm switching technique for the analysis of single phase and three phase motor output voltage and flux(current) distortion factors. By absorbing results, paper concluded that unipolar pwm technique is excellent for single phase motor control. For three phase motor,authors selected three symmetrical carrier wave and obtained less harmonics in output voltage and current. Modified unipolar PWM inverter is reported in [4], to control the magnitude and frequency for unsymmetrical two phase motor.The pwm technique was simulated in matlab and magnitude control of voltage and less harmonics value have been reported.

A pwm current source inverter proposed in [5] shows that, properly selected switching functions can minimize input and output filtering requirements. Selection of the best pwm technique for most applications is accompanied by uncertainty and may lead to poor results. [6]. A scheme is proposed in [7], where both switching pattern of the output and inverter switching frequency are predefined.

Control technique based on dead beat control theory is discussed in [8] using only a voltage sensor and advantages and disadvantages of five different pwm schemes are highlighted in [9].A comprehensive analysis of VSI with respect to phase and amplitude has been presented in [10]. In the proposed method, unipolar and bipolar PWM techniques are used to analyze the output of single phase $\mathrm{H}$-bridge inverter.

FFT analyses are carried out and \% THD is calculated for both unipolar and bipolar pwm techniques, with and without filter using MAT LAB - Simulink software. Hardware implementation is done for unipolar technique since which results in less harmonics.

\section{METHODOLOGY PROPOSED}

Figure1 shows block diagram of the proposed work. Unipolar and bipolar pwm switching techniques are used 
International Journal of Innovative Research in Electrical, Electronics, Instrumentation and Control Engineering

NCAEE 2017

National Conference on Advances in Electrical Engineering

NMAM Institute of Technology, Nitte

Vol. 5, Special Issue 2, April 2017

to turn on the insulated gate bipolar transistor (IGBT's) switches of $\mathrm{H}$-bridge inverter.

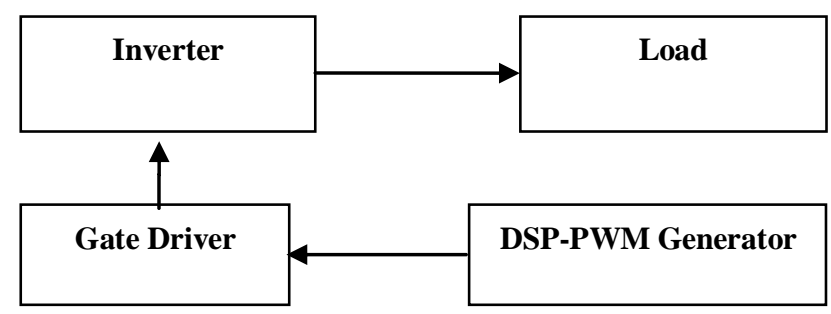

Figure 1. Block diagram of the proposed inverter

With the help of H-bridge inverter ac power is obtained to drive the load. The output voltage of inverter is proportional to the pwm switching pulses. The pwm switching pulses are generated using Dspic (30f2010) controller by comparing reference signal ( $\sin$ wave) and carrier signal (triangular wave).Output of the pwm generator is fed to gate driver in order to drive the $\mathrm{H}$ bridge inverter switches in proper order.

\section{SIMULATION RESULTS AND DISSCUSSION}

In the proposed work, MATLAB-simulation software is used to analyze the performance of inverter with respect to unipolar and bipolar pwm techniques. This section deals with simulation results of both the techniques. In practice, pure sine wave output from inverter is preferred, but it is very difficult to get pure sine wave. In order to obtain sine wave, filter circuit is preferred across the output of the inverter. By the help of Filters one can remove the harmonics in the output of inverter. Low pass filter is used in the simulation circuit.

\section{A. Simulation Circuit of Unipolar Inverter (with filter):}

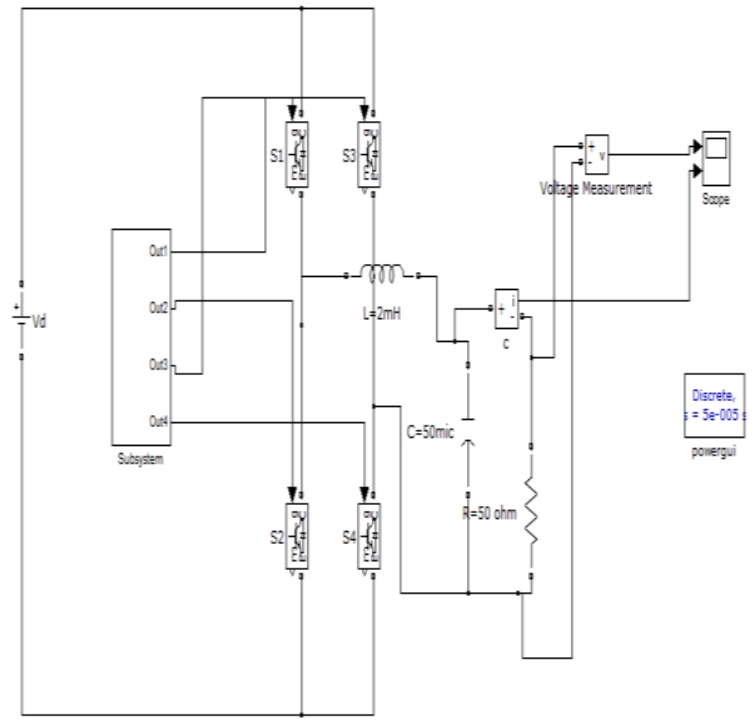

Figure2. Unipolar inverter circuit with filter
Figure 2 shows the Simulink model of unipolar single phase H-bridge inverter circuit with filter. In the proposed method single phase $\mathrm{H}$-bridge inverter is selected for the analysis of simulation results. Four semiconductor switches are used to control the output.

In unipolar pwm switching technique, switching pulses are generated by comparing sine wave (reference) signal and triangular (carrier) signal. While comparing reference signal with carrier signal, if reference signal is greater than carrier signal, high output pulses will be generated and if reference signal is less than carrier signal, we get low output pulses.

By inserting filter circuit one can eliminate the harmonics and that results in pure sine wave output from the inverter. Figure 3 shows the output voltage and current waveforms of unipolar inverter with filter.

It is observed that output voltage and current from the inverter is similar to sine wave, obtained by inserting low pass (LC) filter in the output side of inverter circuit. For (LC) filter, value of the inductances (L) and capacitance (C) are calculated using equation (1).

$$
\mathrm{f}=1 /(2 \pi \sqrt{\mathrm{LC}})
$$

Where, $\mathrm{f}=$ frequency in $\mathrm{Hz}$,

$\mathrm{L}=$ Inductance in Henry and $\mathrm{C}=$ Capacitance in Farad.

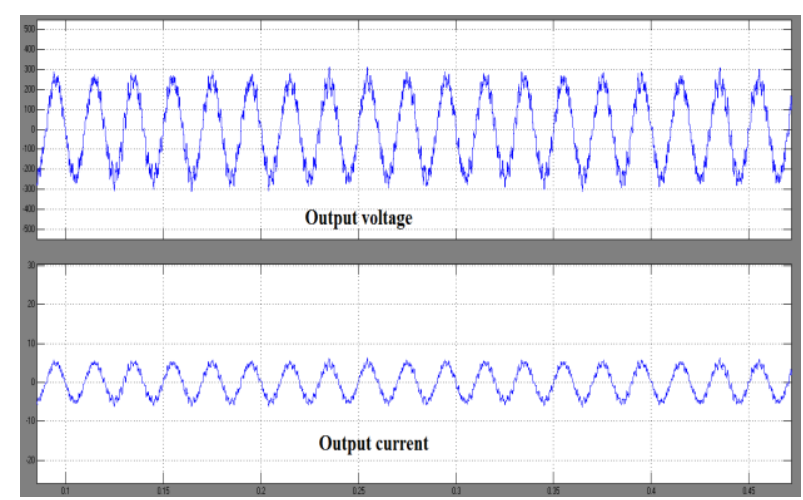

Figure3. Output voltage and current waveforms of unipolar inverter with filter.

B. Simulation Circuit of Bipolar Inverter (with filter):

Figure 4 shows the Simulink model of bipolar single phase H-bridge inverter circuit with filter. Bipolar pwm technique is similar to unipolar pwm switching technique, but in bipolar only one reference signal with zero phase shift is used. Also comparison of reference signal with carrier signal is done such that, when amplitude of carrier triangular wave is greater than reference, high or positive pulses for complete half cycle of the reference signal are generated and when carrier signal is less than reference signal, low or negative pulses will be generated for next half cycle. 


\section{IJIREEICE}

International Journal of Innovative Research in Electrical, Electronics, Instrumentation and Control Engineering

NCAEE 2017

National Conference on Advances in Electrical Engineering NMAM Institute of Technology, Nitte

Vol. 5, Special Issue 2, April 2017

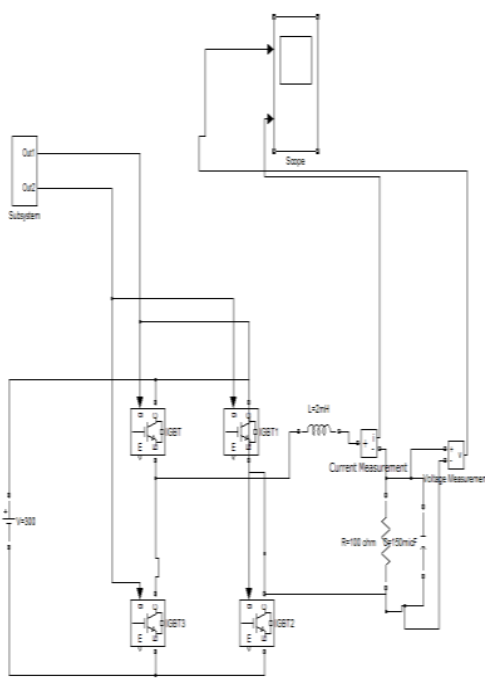

Figure4 Bipolar inverter circuit with filter

Figure 5 shows the output voltage and current waveforms of bipolar inverter with filter.

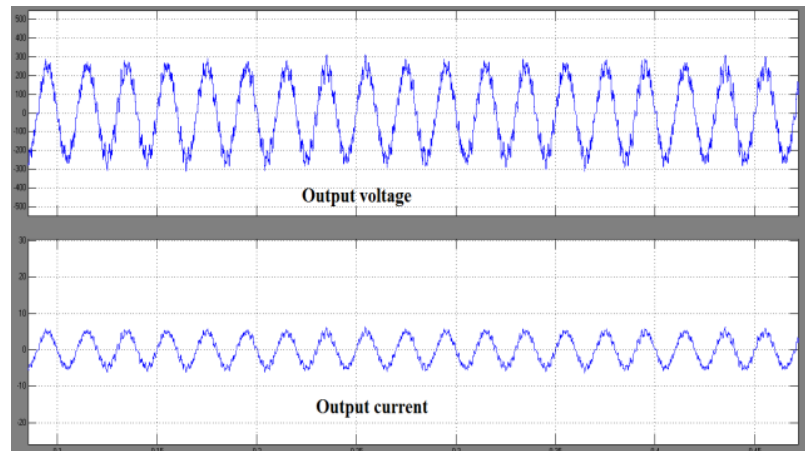

Figure5 Output voltage and current waveforms of bipolar inverter with filter

In the simulation for this case also a low pass (LC) filter has been selected and value of the inductance (L) and capacitance (C) are calculated by equation (1).

C. Harmonic Analysis of Single Phase Inverter for Unipolar and Bipolar PWM techniques:

This section deals with the harmonic analysis of Single Phase Inverter for unipolar and bipolar PWM techniques. The inverter output always contains low and high order harmonics. Theoretically, Total Harmonic Distortion (THD) can be calculated by adding all the components of voltage or current waveform compared against the fundamental component. As per IEEE standard 519, THD must be less than $5 \%$ for all industrial applications.

In the proposed method, for unipolar inverter and bipolar inverter, harmonics are calculated by varying two components of pwm (pulse width modulation) such as amplitude modulation and frequency modulation. Amplitude modulation for both unipolar and bipolar inverter is done by varying the reference sine wave. Frequency modulation is another method used to analyze the harmonic contents of both unipolar and bipolar inverter output. In this case frequency modulation is done by varying switching frequency from $250 \mathrm{~Hz}$ to $1500 \mathrm{~Hz}$.

C1.Amplitude Modulation for Unipolar pwm Technique: Amplitude modulation is carried out by varying pwm reference sine wave in the range of 0.2 to 1.5 volts for both under and over modulation as shown in table1.

Table1: Unipolar pwm Technique

\begin{tabular}{lll}
\hline $\begin{array}{l}\text { Carrier } \\
\text { Frequency }(\mathrm{Hz})\end{array}$ & $\begin{array}{l}\text { Reference Signal } \\
\text { Amplitude }(\mathrm{V})\end{array}$ & $\begin{array}{l}\text { THD } \\
(\%)\end{array}$ \\
\hline 950 & 0.2 & 26.78 \\
950 & 0.4 & 13.21 \\
950 & 0.6 & 9.30 \\
950 & 0.8 & 6.91 \\
$\mathbf{9 5 0}$ & $\mathbf{1}$ & $\mathbf{5 . 2 8}$ \\
950 & 1.2 & 7.01 \\
950 & 1.5 & 16.39 \\
1100 & 0.2 & 39.43 \\
1100 & 0.4 & 17.77 \\
1100 & 0.6 & 13.03 \\
1100 & 0.8 & 9.68 \\
1100 & 1 & 7.72 \\
1100 & 1.2 & 9.78 \\
1100 & 1.5 & 16.39 \\
\hline
\end{tabular}

Total Harmonic Distortion is calculated using FFT (Fast Fourier Transformer) algorithm under mat lab/simulation. Unipolar inverter harmonics are analyzed by amplitude modulation and \% THD (total harmonics distortion) values are also given in table 1.

Table2: Bipolar pwm Technique

\begin{tabular}{lll}
\hline $\begin{array}{l}\text { Carrier } \\
\text { Frequency }(\mathrm{Hz})\end{array}$ & $\begin{array}{l}\text { Reference Signal } \\
\text { Amplitude }(\mathrm{V})\end{array}$ & $\begin{array}{l}\text { THD } \\
(\%)\end{array}$ \\
\hline 950 & 0.2 & 55.39 \\
950 & 0.4 & 30.15 \\
950 & 0.6 & 20.03 \\
950 & 0.8 & 14.04 \\
$\mathbf{9 5 0}$ & $\mathbf{1}$ & $\mathbf{1 1 . 0 3}$ \\
950 & 1.2 & 11.86 \\
950 & 1.5 & 17.49 \\
1100 & 0.2 & 12.4 \\
1100 & 0.4 & 57.30 \\
1100 & 0.6 & 34.55 \\
1100 & 0.8 & 25.26 \\
1100 & 1 & 14.84 \\
1100 & 1.2 & 15.80 \\
1100 & 1.5 & 19.69 \\
\hline
\end{tabular}

As seen from the table1, in the case of unipolar pwm technique, we get minimum THD of $5.28 \%$. 


\section{IJIREEICE}

International Journal of Innovative Research in Electrical, Electronics, Instrumentation and Control Engineering

NCAEE 2017

National Conference on Advances in Electrical Engineering

NMAM Institute of Technology, Nitte

Vol. 5, Special Issue 2, April 2017

C2. Amplitude Modulation for Bipolar pwm Technique:

In the Proposed work, amplitude modulation is also used

to calculate the harmonics in bipolar inverter circuit.

Amplitude modulation is carried out by varying reference sine wave contents in the range of 0.2 to 1.5 volts for both under and over modulation.

Harmonics contents are calculated using FFT (Fast Fourier Transformer) algorithm under mat lab/simulation flat from. Bipolar inverters are analyzed by amplitude modulation and \% THD (total harmonics distortion) values are given in table 2. As seen from table2, THD is nearly double when compare with unipolar technique with respect to same carrier frequency of $950 \mathrm{~Hz}$. From table 1 and table 2, it is observed that values of \% THD are more in bipolar technique compare to unipolar technique.

C3. Frequency Modulation for Unipolar pwm Technique: In frequency modulation, harmonics are calculated by varying the switching frequency with respect to the fundamental frequency $(50 \mathrm{~Hz})$. Modulation Index range, from 5-30 has been used so that maximum switching frequency is $1500 \mathrm{~Hz}$ by keeping fundamental frequency constant at $50 \mathrm{~Hz}$

Table3: Unipolar pwm Technique

\begin{tabular}{llll}
$\begin{array}{l}\text { Modulation } \\
\text { Index } \\
(\mathrm{m})\end{array}$ & $\begin{array}{l}\text { Fundamental } \\
\text { Frequency } \\
(\mathrm{f}) \mathrm{Hz}\end{array}$ & $\begin{array}{l}\text { Switching } \\
\text { Frequency } \\
(\mathrm{m} * \mathrm{f})\end{array}$ & $\begin{array}{l}\text { THD } \\
(\%)\end{array}$ \\
\hline 05 & 50 & 250 & 10 \\
06 & 50 & 300 & 11.28 \\
07 & 50 & 350 & 5.83 \\
08 & 50 & 400 & 7.07 \\
09 & 50 & 450 & 9.45 \\
10 & 50 & 500 & 21.92 \\
11 & 50 & 550 & 6.37 \\
12 & 50 & 600 & 7.84 \\
13 & 50 & 650 & 6.15 \\
14 & 50 & 700 & 6.04 \\
$\mathbf{1 5}$ & $\mathbf{5 0}$ & $\mathbf{7 5 0}$ & $\mathbf{5 . 7 2}$ \\
16 & 50 & 800 & 7.79 \\
17 & 50 & 850 & 24.79 \\
18 & 50 & 900 & 7.73 \\
19 & 50 & 950 & 6.82 \\
20 & 50 & 1000 & 11.72 \\
21 & 50 & 1050 & 77.39 \\
22 & 50 & 1100 & 8.20 \\
23 & 50 & 1150 & 9.50 \\
24 & 50 & 1200 & 10.85 \\
25 & 50 & 1250 & 15.70 \\
26 & 50 & 1300 & 75.73 \\
27 & 50 & 1350 & 24.29 \\
28 & 50 & 1400 & 25.51 \\
30 & 50 & 1500 & 13.26 \\
\hline & & & \\
\hline
\end{tabular}

Total Harmonic Distortions are calculated using FFT (Fast Fourier Transformer) algorithm using matlab/simulation flat form. As seen from the table3, in this technique we get minimum THD of $5.72 \%$ at switching frequency of $750 \mathrm{~Hz}$

C4. Frequency Modulation for Bipolar pwm Technique:

In the proposed method, frequency modulation is applied to calculate the harmonics in bipolar inverter. In frequency modulation, harmonics are calculated by varying the switching frequency with respect to the fundamental frequency $(50 \mathrm{~Hz})$.

Table4 : Bipolar pwm Technique

\begin{tabular}{|c|c|c|c|}
\hline $\begin{array}{l}\text { Modulation } \\
\text { Index } \\
\text { (m) }\end{array}$ & $\begin{array}{l}\text { Fundamental } \\
\text { Frequency } \\
\text { (f) } \mathrm{Hz}\end{array}$ & $\begin{array}{l}\text { Switching } \\
\text { Frequency } \\
(\mathrm{m} * \mathrm{f}) \mathrm{Hz}\end{array}$ & $\begin{array}{l}\text { THD } \\
(\%)\end{array}$ \\
\hline 05 & 50 & 250 & 22.45 \\
\hline 06 & 50 & 300 & 40.47 \\
\hline 07 & 50 & 350 & 15.21 \\
\hline 08 & 50 & 400 & 11.10 \\
\hline 09 & 50 & 450 & 19.42 \\
\hline 10 & 50 & 500 & 18.62 \\
\hline 11 & 50 & 550 & 11.32 \\
\hline 12 & 50 & 600 & 13.88 \\
\hline 13 & 50 & 650 & 14.79 \\
\hline 14 & 50 & 700 & 7.72 \\
\hline 15 & 50 & 750 & 11.20 \\
\hline 16 & 50 & 800 & 13.05 \\
\hline 17 & 50 & 850 & 50.27 \\
\hline 18 & 50 & 900 & 8.21 \\
\hline 19 & 50 & 950 & 14.03 \\
\hline 20 & 50 & 1000 & 19.65 \\
\hline 21 & 50 & 1050 & 13.66 \\
\hline 22 & 50 & 1100 & 25.56 \\
\hline 23 & 50 & 1150 & 19.10 \\
\hline 24 & 50 & 1200 & 16.57 \\
\hline 25 & 50 & 1250 & 18.39 \\
\hline 26 & 50 & 1300 & 14.4 \\
\hline 27 & 50 & 1350 & 56.67 \\
\hline 28 & 50 & 1400 & 52.87 \\
\hline 30 & 50 & 1500 & 24.13 \\
\hline
\end{tabular}

Harmonics contents are calculated using FFT (Fast Fourier Transformer) algorithm under mat lab/simulation environment. Bipolar inverter harmonics are analyzed by frequency modulation and \% THD values are shown in table 4.

As seen from table 4, we get minimum THD value of $7.72 \%$. By observing the tables of THD values for both unipolar and bipolar inverter, we can say that performance of unipolar inverter circuit is better than bipolar inverter circuit. 
International Journal of Innovative Research in Electrical, Electronics, Instrumentation and Control Engineering

NCAEE 2017

National Conference on Advances in Electrical Engineering NMAM Institute of Technology, Nitte

Vol. 5, Special Issue 2, April 2017

\section{HARDWARE RESULTS AND DISSCUSSION}

In order to test the simulation results, hardware is implemented for unipolar inverter (without filter). In the proposed method Dspic30f2010 controller is used. This controller generates the switching pulses to trigger proper switches at proper time period. Output from the gate driver circuit board has been observed using digital storage oscilloscope (DSO) and all G1, G2, G3, \& G4 gate pluses are shown in figures $6,7,8 \& 9$ respectively, which are used to trigger the semiconductor switches.

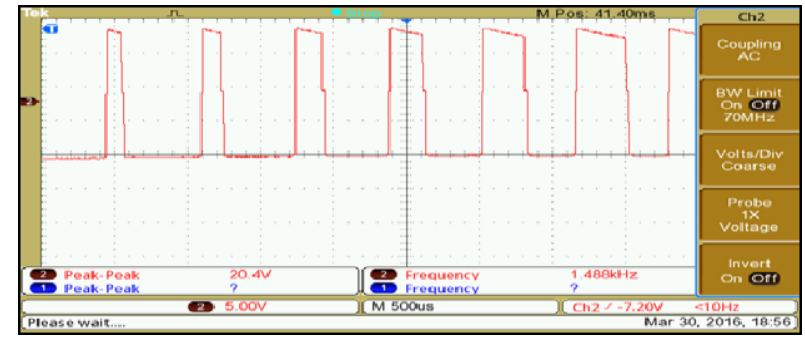

Figure 6 Output from the gate driver board (gate pulses G1).

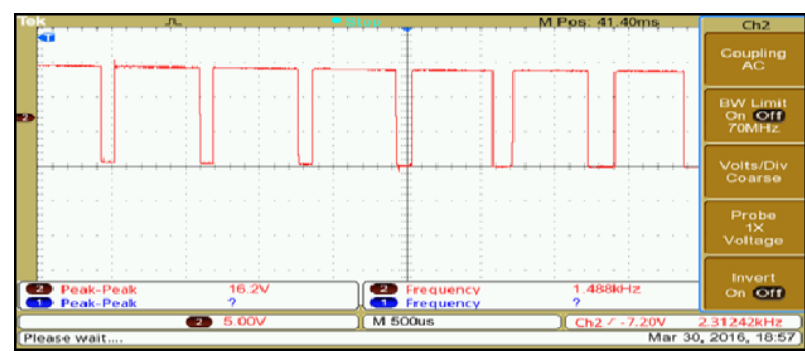

Figure 7 Output from the gate driver board (gate pulses G2).

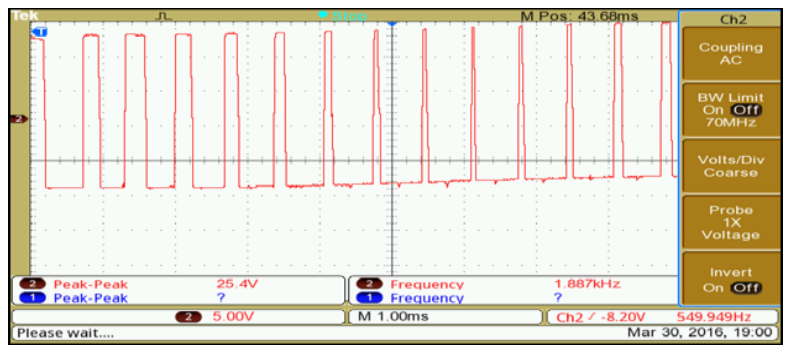

Figure 8 Output from the gate driver board (gate pulses G3).

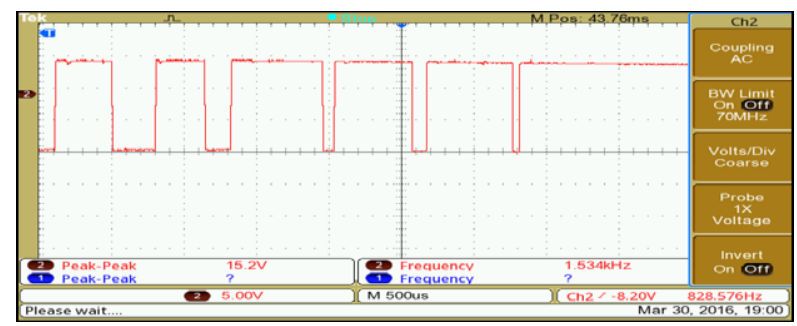

Figure 9 Output from the gate driver board (gate pulses G4).
By mat lab /simulation results, it is observed that unipolar performance is better than bipolar inverter circuit, so for hardware implementation, unipolar H-bridge inverter (without filter) has been selected. The figure 10 shows the output voltage of unipolar H-bridge (without filter) inverter for resistive type of load.

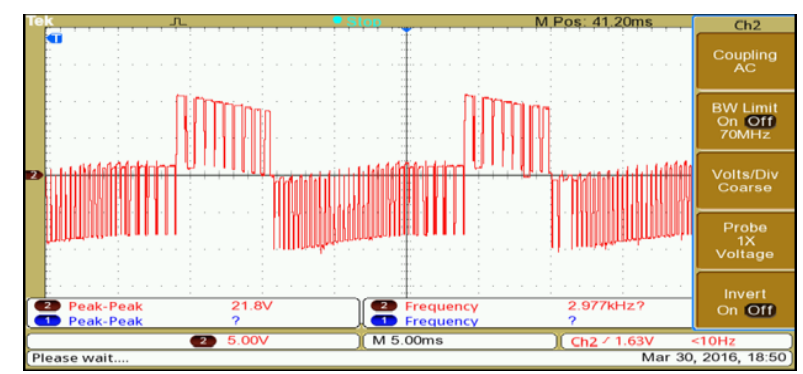

Figure 10 Output of Single Phase Inverter

In hardware implementation, input for the inverter was given 30 volts and output from the inverter was 21.8 (peak- peak). Hence, the hardware results are matches with simulation results.

\section{CONCLUSION}

In this article harmonic content in the output of single phase H-bridge inverter, which employs unipolar and bipolar switching techniques, is analyzed. In order to find the harmonic contents and THD, FFT is used for both the switching techniques using mat lab/simulation software. After verifying simulation results, it is found that performance of unipolar switching technique is better than bipolar switching technique since, minimum value of $\%$ THD of unipolar switching technique is $5.28 \%$ and bipolar switching technique is $11.03 \%$ in case of amplitude modulation. Also in the case of frequency modulation we get $5.52 \%$ and $7.72 \%$ respectively. Hence for hardware implementation unipolar single phase $\mathrm{H}$ bridge inverter (without filter) is selected. THD of inverter can be further reduced by implementing the system with filter and feedback circuits.

\section{REFERENCES}

[1] N.Mohan, T.M.Undeland and W.P.Robbins, "Power Electronics: Converters, Applications and design" (John Wiley and sons, 1989).

[2] N. M. Abdel-Rahim and J. E. Quaicoe, "Analysis and design of a multiple feedback loop control strategy for single-phase voltagesource UPS inverters", IEEE Transactions on Power Electronics, vol. 11 , no. 4 , pp. 532-541, July 1996

[3] J. Kim, J. Hong, K. Nam “ A Current Distortion Compensation Scheme For Four switch Inverters", IEEE Transactions on Power Electronics, Vol. 24, No. 4, April2009, pp. 1032 - 1040

[4] Les Bowtell and Tony Ahfock "Comparison between Unipolar And Bipolar Single Phase Grid Connected Inverters For Pv Applications "Faculty of Engineering Surveying, University of Southern Queensland, Australia.

[5] PhoivosD.Ziogas, Stefanos Manias and Eduardo P. Wiechmann, “ Application of current source Inverters in UPS Systems", IEEE 
National Conference on Advances in Electrical Engineering

NMAM Institute of Technology, Nitte

Vol. 5, Special Issue 2, April 2017

Transactions on Industry Applications, vol. IA20, no. 4, pp. 742752, July/August 1984.

[6] Michael Boost and PhoivosD.Ziogas, "State of the art pwm techniques- A critical Evaluation”, IEEE Conference Publications, pp. 425 - 433, 1986.

[7] P. Enjeti, J.F. Lindsay,P.D. Ziogas and M.H. Rashid,“ New current control scheme for pwm inverters", ", IEEProceedings, vol. 135,Pt.B, no. 4, pp. 172-179, July 1988.

[8] Atsuo Kawamura,ToshimasaHaneyoshi and Richard G. "Dead beat controlled pwm inverters with parameter estimation using only voltage sensor" Hoft,IEEE Conference Publications, pp. 576 - 583, 1988.

[9] Kawamura and Tomoki Yokoyama, "Comparison of five different approaches for real time digital feed back control of pwm inverters" IEEE Conference Publications, pp. 1005 - 1011,vol.2, 1990.

[10] RusongWu,S.B. Dewan and G.R. Slemon, " Analysis of an AC to DC Voltage source converter using pwm with phase and amplitude control",IEEE Conference Publications, pp. 1156 - 1163, vol.1,1989. 